\title{
LA NARRATIVA CUBANA DEL SIGLO XX NOTAS PARA LA RECONSTRUCCIÓN DE UN PROCESO
}

\author{
TEODOSIO FERNÁNDEZ
}

Oculto tras personalidades como Alejo Carpentier y José Lezama Lima, y enmarañado por las disputas entre los defensores y los adversarios del régimen revolucionario institucionalizado desde 1959, el desarrollo de la narrativa cubana del siglo XX no es fácil de seguir. El período anterior a la revolución ha resultado especialmente perjudicado: casi ignorado permanece un proceso similar al seguido por la narrativa hispanoamericana de esa época, con su herencia modernista y naturalista del novecientos, su acercamiento a la naturaleza, su irrupción de los movimientos de vanguardia, su derivación hacia el compromiso político $y$, finalmente, su respuesta a las profundas inquietudes existenciales derivadas de la segunda guerra mundial, en todo momento con personalidades y peculiaridades dignas de atención.

El cosmopolitismo de la tradición modernista - y también su interés creciente en la intimidad de los personajes- estuvo representado especialmente, en vida y en obra, por Alfonso Hernández Catá, desde que en 1907 publicó en Madrid la primera edición de sus Cuentos pasionales hasta que su talento «psicológico» (en versión morbosa y fatalista) culminó con los relatos de Manicomio, editado también en Madrid, en 1931. Simultáneamente otros escritores apoyaban en la tradición naturalista - aunque los límites con el modernismo tampoco fueron claros en Cubasus análisis de una realidad republicana necesitada de regeneración. Novelas significativas a este respecto fueron La honradas (1917) y Las impuras (1919), del médico Miguel Carrión, y Generales y doctores (1920) y Juan criollo (1927), del extrabajador ferroviario Carlos Loveira. En ellos quedó una visión crítica y desesperanzada de la realidad cubana, desde actitudes de denuncia que acentuarían después autores como José Antonio Ramos, en Coaybay (1926) y Las impurezas de la realidad (1929), y Luis Felipe Rodríguez, el más destacado representante de la narrativa cubana «de la tierra» gracias a la novela $L a$ conjura de la ciénaga (1923, reescrita y publicada de nuevo en 1937 como Ciénaga) y a los cuentos de Marcos Antilla, relatos del cañaveral (1932).

Esa narrativa se hacía eco de la atmósfera cada vez más asfixiante que se respiraba bajo la dictadura de Gerardo Machado, hasta su caída en 1933. Pero la actitud de los intelectuales aún había de radicalizarse después, frente a la presión norteamericana que condicionó la actuación del presidente provisional Carlos Manuel de Céspedes y determinó luego la de Fulgencio Batista, jefe del ejército que entre 1934 y 1940 vigiló la política nacional. En ese clima se acentuó el compromiso de los escritores con la realidad social y política del país, en beneficio de la orientación realista que ya antes parecía dominante entre los narradores cubanos, capaz de conciliar la tradición del naturalismo con inquietudes de signo socialista. Frutos característicos de la época pueden encontrarse en las novelas históricas El negrero. Vida novelada de Pedro Blanco Fernández de Trava (1933), de Lino Novás Calvo, y Caniquí. Trinidad, 1830 (1936), de José Antonio Ramos, o en Hombres sin mujer (1938), donde Carlos Montenegro narró sus implacables experiencias de quince años de cárcel, y en los 
«testimonios» de Pablo de la Torriente Brau -Realengo 18, Presidio Modelo, Aventuras del soldado desconocido cubano-, difundidos después de que muriera en combate durante la guerra civil española. Esa fue la orientación dominante en la época, aunque no impidió que se manifestasen propuestas ajenas a la tradición realista y costumbrista: las novelas «gaseiformes» de Enrique Labrador Ruiz - El laberinto de sí mismo (1933), Cresival (1936) y Anteo (1940) - fueron las más radicales, pero pueden inscribirse en esta otra opción obras como Jardín, la «novela lírica» que Dulce María Loynaz escribió hacia 1935 aunque no se publicase hasta 1951, e incluso como EcueYamba-O (1933), donde Alejo Carpentier, desde Europa, dejó constancia de su interés por los ritos afrocubanos, fascinantes para quien en lo atávico e irracional encontraba manifestaciones de una intuición poética de la realidad. Por entonces ya relacionaba esas formas culturales con la posibilidad de recuperar la armonía de los orígenes, con el acceso a verdades profundas de la naturaleza humana ${ }^{1}$.

Con la segunda guerra mundial la atmósfera política cambió bruscamente. La guerra civil española había colocado a la mayoría de los intelectuales cubanos al lado del bando republicano derrotado, pero los avatares del nuevo conflicto -el pacto entre Hitler y Stalin primero, la alianza de la Unión Soviética con el capitalismo europeo y norteamericano después - sembraron un desconcierto al que no fue ajena la situación interna: Fulgencio Batista accedió a la presidencia en 1940 con el apoyo de un frente popular en que se integraron los comunistas, y entre sus ministros se contaron personalidades tan significativas de la izquierda como Juan Marinello y Carlos Rafael Rodríguez. Con la guerra fría llegaría el fin de esa alianza, y la hostilidad culminaría cuando, tras los gobiernos del Partido Revolucionario Cubano ("Auténtico») de Grau San Martín (1944-1948) y Prío Socarrás (19481952), Batista dio un golpe de estado y se instaló en el poder para quedarse hasta que Fidel Castro entrara triunfante en La Habana el 1 de enero de 1959.

Esas dos décadas habían de ser extraordinariamente ricas para la literatura cubana. Eran varios los escritores notables que continuaban en actividad, como Novás Calvo, autor de La luna nona y otros cuentos (1942) y traductor excelente de Hemingway y otros es- critores norteamericanos e ingleses, y Labrador Ruiz, que prolongó su práctica vanguardista con los relatos reunidos en Carne de quimera («novelines neblinosos», 1947) y Trailer de sueños (1949), para adoptar un registro más realista en la novela $L a$ sangre hambrienta (1950) y en los cuentos de El gallo en el espejo (1953). Una orientación costumbrista y crítica se concretó en novelas como Fotuto (1948), de Miguel de Marcos, y cabe resaltar el interés de los relatos que Onelio Jorge Cardoso incluyó en Taita, diga usted cómo (1945) o El cuentero (1958). Además, es en esta época cuando se produce la irrupción decidida de la narrativa cubana en el ámbito literario de Hispanoamérica, irrupción que ha de relacionarse necesariamente con Alejo Carpentier y su descubrimiento de lo real maravilloso americano. Ecue-Yamba $O$ ya había sido una consecuencia de la visión de América Latina como un mundo ajeno a la razón y a la ciencia. En los años veinte esa convicción estaba muy extendida en París, donde Carpentier contó con las propuestas del surrealismo para aderezar los atractivos de su tierra natal. En Haití, en 1943, recibiría la revelación definitiva de la condición maravillosa de aquella realidad, revelación que divulgó en 1948 desde el periódico El Nacional de Caracas, y que tuvo extraordinarias consecuencias literarias: las novelas El reino de este mundo (1949) y Los pasos perdidos (1953) serían sus mejores aportaciones personales a la configuración de una de las más persistentes visiones contemporáneas de Latinoamérica, una geografía habitada por mitos ancestrales, escenario de hechos que convertirían su historia en una crónica de lo real maravilloso, ámbito en el que intentar el viaje imposible hacia los orígenes del hombre.

La significación de Carpentier ha sido suficientemente estudiada, y quizá resultó más decisiva para el desarrollo de la novela hispanoamericana en su conjunto que para el de la cubana en particular. Para entender lo que había de ocurrir en la isla quizá conviene recurrir a las diferencias que enfrentaron por entonces a José Lezama Lima y a Virgilio Piñera, a ese conflicto «entre dos estéticas - dos visiones del mundo, en realidad-opuestas e irreconciliables, que en buena parte determi-

ALEJO GARPENTIER

EL REINO

DE ESTE MUNDO

(Relato)
E. D. I. A. P. S. A.

Mero Americana de Publicaciones, S.A. 1949
1 Con esa significación y con el interés de la época por los sectores populares ha de relacionarse la atención a los temas afrocubanos que se concretaría en recopilaciones de cuentos y leyendas como ¡iOh, mío Yemayá!! (1938) de Rómulo Lachatañeré, Cuentos negros de Cuba (1940), de Lydia Cabrera, y Cuentos y leyendas negras de Cuba (1942), de Ramón Guirao. 


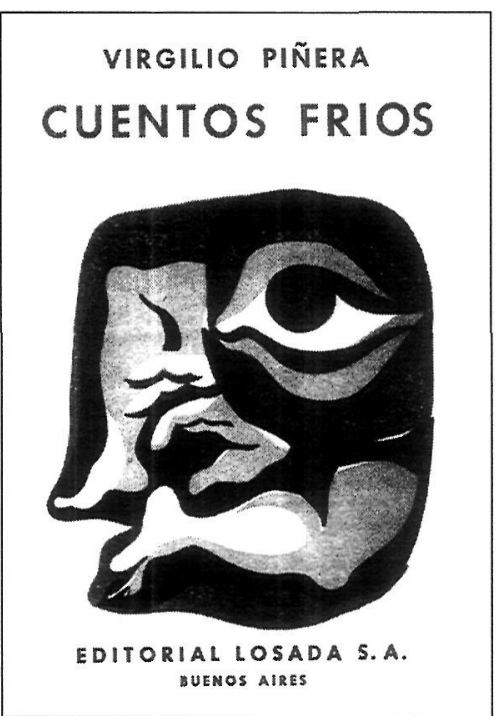

nan algunas tendencias de la literatura cubana hasta nuestros días» ${ }^{2}$. Desde luego, esas diferencias no tuvieron una repercusión inmediata en la narrativa cubana, aunque Piñera ya enriquecía con su novela La carne de René (1952) y con sus Cuentos fríos (1956) la corriente existencialista que toda su obra literaria representaba, una obra insolente, irónica, muy interesada en el absurdo de la existencia, en decidida oposición a Lezama Lima y al grupo «Orígenes». Aunque residió en Buenos Aires de 1946 a 1958, Piñera colaboró activamente en la revista Ciclón (1955-1957 y 1959), que preparó el terreno por 2

Remedios Mataix, La escritura de lo posible. El sistema poético de José Lezama Lima, Universitat de Lleida, Asociación Española de Estudios Literarios Hispanoamericanos, 2000, pág. 96.

3

Mea Cuba, Barcelona, Plaza\&Janés Editores/Cambio 16, 1992, pág. 78

4

Fidel Castro, Palabras a los intelectuales, La Habana, Ediciones del Consejo Nacional de Cultura, 1961 (Año de la Educación), pág. 11.

La narrativa cubana del Siglo XX Notas para la reconstrucción de un proceso

TEODOSIO FERNÁNDEZ donde, llegado el triunfo de Fidel Castro, había de circular Lunes, el suplemento literario semanal del diario Revolución. De hecho $\mathrm{C} i-$ clón ya se había publicado en un clima de agitación, signado por los sucesos de 1956: en abril se desarticuló una conspiración militar contra Batista y en diciembre Fidel Castro desembarcó del Gramma en la provincia de Oriente, iniciando la lucha revolucionaria.

Ciclón tuvo oportunidad de coincidir en 1959 con Lunes de Revolución, que empezó a salir en marzo con la pretensión de llevar el entusiasmo revolucionario al ámbito de la cultura. Guillermo Cabrera Infante, director del suplemento, recordaría mucho después aquel «huracán» que arrasó con muchos escritores del momento: «Teníamos el credo surrealista por catecismo y en cuanto estética, al trotskismo, mezclados, con malas metáforas o como cóctel embriagador» ${ }^{3}$. Esa nueva conjunción de surrealismo y trotskismo, que recuerda confluencias pasadas - en especial el en México, en 1938, y la participación de ambos en la redacción del manifiesto «Por un arte revolucionario independiente»-, conciliaba el espíritu de Ciclón con el entusiasmo revolucionario que exigía la época; respondía a la voluntad declarada de llevar el arte a la vi$\mathrm{da}$, de aproximarlo al medio político, social y económico en que surgía, y de aprovechar sistemas de acercamiento a la realidad como la dialéctica materialista, el psicoanálisis y el existencialismo. La fusión de la vanguardia artística con la vanguardia social y política parecía posible a los colaboradores de Lunes que asumían las obligaciones del intelectual revoencuentro de André Breton con León Trotsky lucionario, implicado en un proceso histórico-social orientado hacia la construcción del socialismo. Virgilio Piñera se encontraba entre ellos, y en ese clima pudo convertirse en la referencia preferida por los escritores más jóvenes, los mismos que creían necesaria la descalificación de Lezama Lima, a pesar de su actitud receptiva e incluso entusiasta hacia los cambios políticos acaecidos.

Pero la identificación de Lunes con la revolución pronto quedó en entredicho. El fin de la publicación se puede relacionar con la protesta de sus colaboradores contra el secuestro de P.M., un reportaje cinematográfico dirigido por Sabá Cabrera y condenado por contrarrevolucionario. El asunto motivó las reuniones celebradas en la Biblioteca Nacional en junio de 1961, y que dieron pie para que Fidel Castro pronunciara sus famosas «palabras a los intelectuales»: «¿Cuáles son los derechos de los escritores y de los artistas revolucionarios o no revolucionarios? Dentro de la Revolución, todo; contra la Revolución ningún derecho», advirtió ${ }^{4}$. En noviembre Lunes dejó de salir. Por entonces sufrió Piñera las consecuencias de las primeras medidas represivas contra los homosexuales, y Severo Sarduy, ligado a Ciclón y colaborador asiduo de Lunes, decidió no regresar a la isla cuando en diciembre de ese año finalizó el tiempo por el que había sido enviado a París para estudiar crítica de arte, becado por el gobierno cubano. El «período romántico» de la revolución había concluido, aunque durante algún tiempo la discusión todavía fue posible y los narradores pudieron elegir las opciones que consideraron más convenientes, incluido Piñera, que aún publicaría las novelas Pequeñas maniobras (1963) y Presiones y diamantes (1967). La primera apareció en Ediciones R (de Revolución), desde donde se habían difundido obras de los escritores ligados a Lunes - como Así en la paz como en la guerra (1960), donde Cabrera Infante reunió sus primeros relatos- y donde pudieron seguir publicando hasta 1964. También hasta esa fecha encontraron acogida en la revista Casa de las Américas, dirigida por Haydée Santamaría. Las dificultades se acentuaron después, con las consecuencias conocidas: Cabrera Infante, agregado cultural en Bruselas desde 1962 hasta 1965, optó por el exilio en octubre de ese último año, y no tardaría en seguirlo Calvert Casey, colaborador de Lunes y de Casa de las Américas, autor de 
los cuentos de El regreso publicados por Ediciones $\mathrm{R}$ en 1962. Luego llegarían los problemas para Heberto Padilla, que también había colaborado activamente en Lunes desde Londres, donde era corresponsal de la agencia Prensa Latina, y que provocó el fin de la primera época de la revista El Caimán Barbudo - había iniciado su andadura en 1966, y hubo de cambiar de dirección y de rumbo a principios de 1968- al publicar sus críticas a Pasión de Urbino, de Lisandro Otero, y sus elogios a Tres tristes tigres, de Cabrera Infante, novelas editadas en 1967.

Con la perspectiva de los años transcurridos, puede advertirse que la narrativa cubana se vio obligada a elegir entre dos opciones fundamentales: la que representaron Virgilio Piñera y los escritores surgidos en torno a Ciclón y Lunes - y que terminaría comprometiendo a Jesús Díaz y otros "caimanes» que habían utilizado el cuento para dar cuenta de sus inquietudes juveniles-y la que consiguió ajustarse a los planteamientos culturales del régimen castrista. Lezama Lima quedó en un territorio propio, desde luego más expuesto a los ataques de Lunes y su círculo que a los de la línea oficial, integrado como estuvo en los organismos culturales creados por la revolución. Pudo observar con preocupación las trabas que obstaculizaron la difusión de su novela Paradiso (1966), culpable de desviaciones sexuales e inquietudes o tentaciones metafísicas, pero nadie resultaría más molesto para él que Heberto Padilla, quien en 1959, desde las páginas de Lunes, lo acusó de mantenerse ajeno a los cambios que se operaban en el país - eso no impidió que Lezama colaborase reiteradamente en el semanario-, y en abril de 1971, en la confesión con que culminó su célebre "caso», lo hizo responsable de opiniones negativas sobre la revolución ${ }^{5}$. En consecuencia, Paradiso supuso una presencia insólita e incómoda en el panorama de la narrativa cubana de los años sesenta, inmersa en un proceso que generaba disidencias sucesivas: la siguiente digna de mención iba a ser la de Reinaldo Arenas, acogido en La Habana por Virgilio Piñera, distinguido por Celestino antes del alba con una Mención Especial del Premio Cirilo Villaverde de la UNEAC, que editó esa novela en 1967, y condenado al exilio interior desde que publicara en México El mundo alucinante (1969).
Las narraciones de Piñera, Sarduy, Cabrera Infante o Arenas son tan personales que difícilmente puede encontrarse en ellas un denominador común. Deben, sí, relacionarse con la orientación surrealizante de Ciclón, convertida al «trotskismo» de Lunes por la necesidad de adaptarse a las exigencias de la revolución y favorecida por la pretensión oficial de atraer hacia Cuba a la izquierda intelectual del mundo entero, pero que siempre mantuvo un carácter vanguardista e independiente, propicio al desarrollo de experiencias tan originales como las que se concretaron en las obras de esos autores. Desde la perspectiva oficial quedaría pronto al descubierto la debilidad de sus fundamentos ideológicos, más evidente en la medida en que el régimen precisaba e imponía su política cultural frente a las algaradas vanguardistas y las inquietudes existenciales. $\mathrm{Al}$ principio se trató de potenciar opciones literarias acordes con la democratización o popularización de la cultura pretendida por las campañas de alfabetización y educación impulsadas por el gobierno, con lo que las experiencias de vanguardia quedaban relegadas al ámbito de los valores burgueses que se quería desterrar. La preferencia por el realismo «socialista» sería consecuente con el proceso seguido por el régimen castrista. Al explicar esa elección conviene tener en cuenta la evolución de las relaciones de Fidel Castro con los comunistas cubanos, que no habían sido buenas en tiempos de Batista. En 1961 éstos habían confluido con los revolucionarios del Movimiento 26 de Julio en el Partido Unido de la Revolución Socialista, y empezaron a ocupar cargos importantes en el gobierno. En 1965 el propio Castro asumía la dirección del recién creado Partido Comunista de Cuba, que celebró entonces su Primer Congreso.

La sucesión de disidencias o deserciones no impidió que en la isla se desarrollase una narrativa de la revolución con características peculiares, atenta a los avatares de la política cultural del castrismo. Su punto de partida es difícil de precisar, pues las preocupaciones de la mayoría de las novelas publicadas durante los primeros años del régimen revolucionario pueden interpretarse como pervivencia de la novela de la tierra o de la narrativa costum-
5

Véase Remedios Mataix, «Del anatema al diálogo. Lezama y la Revolución», en op. cit., págs. 183-218.

La narrativa cubana del Siglo XX Notas para la reconstrucción de un proceso

TEODOSIO FERNÁNDEZ 


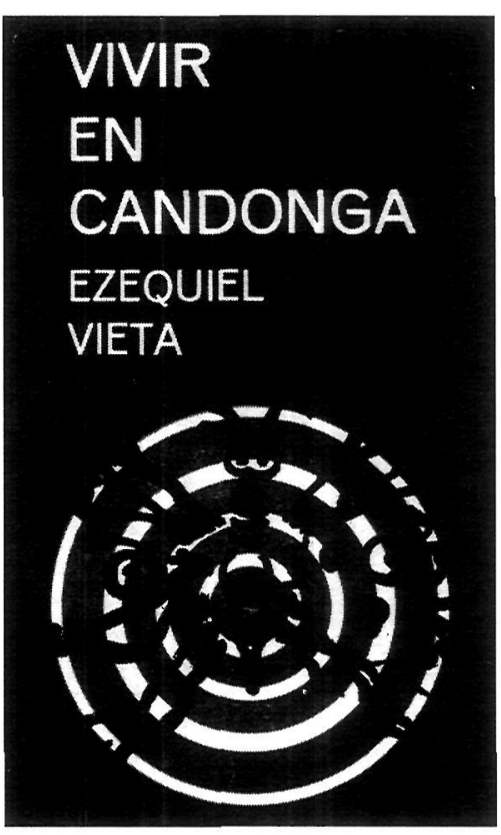

6

Rogelio Rodríguez Coronel, La novela de la revolución cubana, La Habana, Editorial Letras Cubanas, 1986, pág. 71.

7

Véase Rodríguez Coronel, op. cit., págs. 81 y 104

8

José Antonio Portuondo, «Una novela revolucionaria», en Casa de las Américas, núm. 71, marzo-abril de 1972, págs. 105106 (106).

La narrativa cubana del Siglo XX Notas para la reconstrucción de un proceso

TEODOSIO FERNÁNDEZ brista de crítica social. Bertillón 166 (1960), de José Soler Puig, fue quizá el primer resultado significativo e inequívoco de la nueva época, dentro de un panorama ciertamente dominado por la novela existencial, «de clara raigambre sartreana» ${ }^{6}$, lo que por entonces concordaba con la atmósfera cultural cubana: Jean-Paul Sartre visitó la isla en 1960, y Lunes de Revolución celebró su presencia con entusiasmo. Soler Puig recreaba la lucha contra Batista desarrollada en Santiago de Cuba, donde la actividad revolucionaria había tenido su centro desde el asalto al Cuartel Moncada, en 1953. La atmósfera asfixiante de la dictadura se veía afectada por la seguridad de su próximo fin, con lo que los conflictos característicos de la novela existencial —los del hombre alienado y sus posibilidades de desalienación- empezaban a ser reemplazados por otros que enfrentaban la opresión del gobierno de Batista a la liberación revolucionaria. En esa línea, la narrativa cubana de la revolución supo plantear otros conflictos ${ }^{7}$, como el que a la ignorancia y a la pobreza opuso las civilizadoras conquistas revolucionarias en Memorias del subdesarrollo (1965), de Edmundo Desnoes, o el que en Vivir en Candonga (1966), de Ezequiel Vieta, enfrentó el espacio de la ilusión o del mito, el refugio construido por quienes pretendieron vivir al margen del proceso cubano, con la historia que terminaría por arrollarlos.

Ninguna de estas opciones se atenía al discurso antirracionalista dominante en la narrativa hispanoamericana del boom de los años sesenta. Más bien trataban de construir una historia propia, superando las limitaciones sociales, políticas y culturales de la época prerrevolucionaria, y desde esa perspectiva carecían de significación los valores que la literatura de inquietudes existenciales había asignado a la naturaleza y al mito: dejaron de constituir una salida para el alienado habitante de los núcleos urbanos, pues, además de que la lucha revolucionaria se desarrolló tanto en el campo como en la ciudad y el nacimiento del hombre nuevo había de potenciarse en todos los medios, tendió a verse el mundo campesino como un ámbito retardatario, reacio a aceptar los cambios procurados por la revolución. A este respecto había de resultar especialmente significativa La última mujer y el próximo combate (1971), donde Manuel Cofiño López mostró los esfuerzos y dificultades para aplicar el plan de desarrollo forestal y agrario en un medio rural lastrado no sólo por intereses económicos reaccionarios, sino por las creencias y mitos que conforman una visión precientífica de la realidad. Al reseñar esa novela, José Antonio Portuondo vio en ese plan de desarrollo «el polo opuesto de Macondo», y señaló que «lo mágico, lo 'real maravilloso' es aquí la visión caduca y pintoresca, mítica que va quedando atrás, sobrepasada sin violencia por la nueva conciencia socialista, científica, revolucionaria» ${ }^{8}$. Aunque Cofiño estuviera más acertado al mostrar ese mundo en desaparición que al presentar a sus héroes revolucionarios, es indudable que proponía abandonar el discurso narrativo de lo real maravilloso o del realismo mágico y sustituirlo por otra orientación realista y asequible, ajena a la alegorización o mitificación de la realidad hispanoamericana que Alejo Carpentier y Gabriel García Márquez habían ofrecido.

Así parecía imponerse un realismo socialista que trató de mantenerse ajeno a los dogmatismos que en otros tiempos y latitudes habían esterilizado la producción literaria. Lo hizo también a costa de las experiencias formales que se habían hecho frecuentes a mediados de los sesenta, pues la novela de la revolución había procurado aderezar la presentación de sus temas preferidos - los escritores se centraron primero en la crítica de la etapa republicana y en los avatares de la lucha revolucionaria, para interesarse luego por los procesos sociales desencadenados por la revolución y los cambios de mentalidad que exigía - con técnicas narrativas novedosas, las mismas que en otros países latinoamericanos contribuían por entonces a la modernización de la narrativa, y que en Cuba pronto fueron descalificadas como muestra de una nueva dependencia colonial. En el desarrollo de ese proceso resulta significativo el gran predicamento de que gozó el testimonio (reportajes, memorias, diarios de campaña), un género de condición literaria discutible, pero valorado por su fidelidad a las experiencias personales y a la historia reciente. Su variedad más próxima a la ficción fue la novela-testimonio, que obtuvo su primer éxito relevante con Biogra- 
fía de un cimarrón (1966), donde Miguel Barnet reconstruía la vida de Esteban Montejo desde sus tiempos de esclavo hasta el triunfo de la revolución: un siglo de historia cubana, cuya verosimilitud se reforzaba con el respaldo de la formación etnológica del autor.

Esa derivación hacia el realismo socialista estaba en consonancia con la radicalización del régimen, que se acentuó paulatinamente a partir de 1968. Cuando la Casa de las Américas creó un premio para el testimonio -el primero se concedió en 1970 a la uruguaya María Esther Gilio por La guerrilla tupamarala cultura oficial ni siquiera estaba interesada en los trabajos etnológicos o antropológicos que dieran voz a los sectores populares: tras publicar La canción de Rachel (1969), Barnet había iniciado una etapa de silencio que se prolongaría durante más de una década, y el norteamericano Oscar Lewis, patrocinador de la «antropología de la pobreza», se vio obligado a interrumpir en junio de 1970 el trabajo que lo había llevado hasta la isla el año anterior, invitado por el propio gobierno cubano. En esa tesitura, los narradores tuvieron buen cuidado de evitar las tentaciones «metafísicas», sobre todo desde que Fidel Castro, al clausurar el Primer Congreso de Educación y Cultura celebrado en La Habana en abril de 1971 - su lema fue «el arte es un arma de la Revolución»-, dejó claros los límites de lo permitido: «Nuestra valoración es política. No puede haber valor estético sin contenido humano. No puede haber valor estético contra la justicia, contra el bienestar, contra la liberación, contra la felicidad del hombre. ¡No puede haberlo!»9. La narrativa cubana quedaba abocada a sustituir los conflictos existenciales determinados por el impacto de la revolución en las mentalidades prerrevolucionarias por otros relacionados con el presente y con el futuro, en los que el pasado debía contar sobre todo en la medida en que preparaba la revolución.

No es fácil comprobar el impacto de ese proceso fuera de la isla. La revolución cubana sin duda fue un estímulo para que los escritores latinoamericanos saliesen del pesimismo existencialista - las circunstancias históricas de los cincuenta no habían sido alentadoras para los intelectuales de izquierda: los norteamericanos intervinieron en Guatemala para derrocar al presidente Jacobo Arbenz, cayó el peronismo en Argentina, se descubrieron los crímenes de Stalin-y recuperasen la confianza en la historia. La mayoría entendió que en Cuba se había instaurado un socialismo distinto al representado por la Unión Soviética y por el realismo socialista, y los más fieles no cambiaron de opinión cuando Fidel Castro apoyó la invasión de Checoslovaquia por las tropas del Pacto de Varsovia, ni después con el «caso Padilla»: el período romántico de la revolución nunca concluyó para ellos, de modo que pudieron seguir adentrándose en las dimensiones mágicas o fantásticas de la realidad que el surrealismo había ayudado a descubrir, convencidos de que la literatura podía propiciar el cambio de mentalidad frente a las mentiras oficiales que sostenían en Hispanoamérica un orden social injusto, seguros de que el mito constituía un medio para modificar las estructuras mentales, asociando el antirracionalismo - la herencia surrealista seguía activa- con las transformaciones sociales acarreadas por la revolución. Desde luego, el eco de las exigencias revolucionarias se advierte en la polémica que en 1969 enfrentó al colombiano Óscar Collazos con Julio Cortázar y Mario Vargas Llosa en las páginas uruguayas de $M$ arcba ${ }^{10}$, en la pretensión de Cortázar de intentar con Libro de Manuel su Rayuela política, o en la renuncia explícita al discurso mágico-realista que el peruano $\mathrm{Ma}$ nuel Scorza hizo en La tumba del relámpago, la última novela de su saga «La guerra silenciosa». Esas evidencias, y muchas otras que podrían recordarse, no modifican la impresión de que la narrativa cubana de la revolución siguió un proceso propio, y que ese proceso limitó su interés: ninguna de esas novelas alcanzó el reconocimiento logrado por Paradiso, Tres tristes tigres o El mundo alucinante.

En 1971 se considera iniciado el «quinquenio gris» de la cultura cubana de la revolución. La relación de las novelas publicadas permite comprobar que (salvo 1972, en que no apareció ninguna) esos años no fueron mucho peores que otros anteriores, y a ellos pertenecen obras como Cuando la sangre se parece al fuego (1975), de Cofiño López, El pan dormido (1975) y El caserón (1976), de Soler Puig, y otras de autores también muy conocidos en el medio, como César Leante o Miguel Collazo. En 1974 se editaron asimis-
9

Fidel Castro, "Discurso de clausura», en Casa de las Américas, núms. 65-66, marzo-junio de 1971, págs. 21-33 (28)

10

Véase Óscar Collazos, Julio Cortázar y Mario Vargas Llosa, Literafura en la revolución y revolu ción en la literatura, México, Siglo XXI Editores, 1970.
La narrativa cubana del Siglo XX Notas para la reconstrucción de un proceso

TEODOSIO FERNÁNDEZ 
11

Véase Begoña Huertas, Ensayo de un cambio. La narrativa cubana de los ' 80 (Premio Casa de las América de Ensayo, 1993), La Habana, Casa de las Américas, 1993, págs. 50-51.
La narrativa cubana del Siglo $\mathrm{XX}$ Notas para la reconstrucción de un proceso

TEODOSIO FERNÁNDEZ mo El recurso del método y Concierto barroco, del consagrado Alejo Carpentier, quien, consciente de las dificultades que entrañaba la lectura revolucionaria de sus primeras obras, desde El siglo de las Iuces (1962) había ensayado una adaptación al medio que culminaría con La consagración de la primavera (1978), la novela que (quizá contra García Márquez) mejor había de responder a su proclamada convicción de que con la revolución cubana habían terminado los tiempos de la soledad y empezaban los de la solidaridad. Por otra parte, la necesidad de encontrar soluciones narrativas de menor riesgo facilitó el desarrollo de una novela policial adaptada al medio, normalmente protagonizada por investigadores positivos que contaban con la colaboración del pueblo para perseguir a delincuentes que eran además contrarrevolucionarios. Otro tanto ocurría con las novelas de espionaje, que normalmente enfrentaron a los servicios de seguridad cubanos con la CIA y los enemigos internos y externos de la revolución.

El quinquenio gris se da por terminado en 1976, cuando desde el recién creado Ministerio de Cultura se empezó a reorientar la política cultural del régimen. Fue también el año de la muerte de Lezama Lima, lo que reclamaría nueva atención sobre su obra, enriquecida en lo referente a la narrativa con la publicación de Oppiano Licario (1977). Con La consagración de la primavera y El arpa y la sombra (1979), Carpentier contribuyó a dar la impresión de que la novela se recuperaba en el país, también con la colaboración de Cintio Vitier, poeta de «Orígenes» que descubría su «modesto ser histórico» en De Peña Pobre. Memoria y novela (1979), y de Antonio Benítez Rojo, que con El mar de las lentejas (1979) se sumaba a la renovación de la novela histórica, por citar algunas obras significativas de los últimos años setenta. Pero la situación sólo se vio verdaderamente abocada a un cambio a partir de 1980, desde que miles de cubanos (entre ellos, Reinaldo Arenas) consiguieron abandonar el país por la embajada peruana y el puerto del Mariel, y quedaron definitivamente en evidencia las limitaciones del régimen castrista. El momento de inflexión para los narradores puede situarse en torno a esa fecha, con las Jornadas de Narrativa Cubana que se celebraron en Santiago de Cuba en 1979, 1980 y 1981. En los años siguientes se repetirían los encuentros y la discusión, también sobre el papel de la crítica, mientras la revolución entraba en un «período de rectificación» que la literatura asumiría también.

La narrativa cubana de los ochenta adquiriría así características nuevas dentro de la isla, derivadas de la apertura que sucedió a los esquemas ideológicos de antaño. Novelas como Un rey en el jardín (1983), de Senel Paz, Las iniciales de la tierra (1987), de Jesús Díaz, u Oficio de ángel (1989), de Miguel Barnet, recurrían a la memoria para recuperar la infancia o la adolescencia desde la madurez del narrador, mientras otras preferían abordar el presente inmediato, como Un tema para el griego (1987), de Jorge Luis Hernández, o Fabriles (1988), de Reinaldo Montero ${ }^{11}$. En alguna ocasión parecieron recuperarse orientaciones latinoamericanas perdidas - como la del realismo mágico y la de lo real maravilloso cifrado en la cultura afrocubana-, y desde luego algunos jóvenes se mostraron interesados en rescatar las opciones de los años sesenta que se habían cultivado en la isla y después habían quedado marginadas: aquéllas que habían preferido la lírica a la épica, y que no habían desdeñado la experimentación de técnicas narrativas y la innovación lingüística. No es que la novela cubana de los ochenta se sintiese especialmente proclive al experimentalismo: la riqueza y complejidad del discurso narrativo era en muchos casos una exigencia de la subjetivización ahora dominante en la ficción, de la preferencia por la reflexión sobre la acción. En realidad, más que retornar a posiciones del pasado, la narrativa cubana de la isla se incorporaba al proceso que la narrativa seguía en otros países de Latinoamérica, impulsado por escritores que habían sufrido la represión y el exilio a causa de dictaduras sangrientas, o simplemente se habían sentido afectados por el desencanto que se extendió por entonces ante el fin de las utopías.

Las peculiaridades del pasado reciente hacían más notoria en Cuba la sustitución de la épica colectiva de la revolución por las perspectivas individuales, del objetivismo realista por un discurso interiorizado e incluso lírico. Aunque sólo tratasen de participar en el proceso revolucionario de rectificación - la condena del castrismo quedaba exclusivamente a cargo de los que habían optado por el exilio-, los narradores cubanos también se mostraron ahora interesados en la recuperación del tiem- 
po perdido desde la experiencia personal, sin maniqueísmos ni juicios de valor. Esa narrativa de la memoria coexistió con la que abordaba el presente desde una perspectiva circunstancial, sin pretensiones abarcadoras, a veces con una visión humorística que había sido ajena a la narrativa de la revolución. Ambas opciones iniciaban así la revisión de los logros alcanzados y de los fracasos sufridos, lo que significaba de hecho tomar posiciones ante el proceso vivido por el país, e incluso adoptar formas diversas de crítica y de autocrítica. De ese modo los escritores daban cuenta de una realidad revolucionaria pero también trivial y a veces dolorosa, tan cotidiana como el amor y la muerte.

Esa orientación había de acentuarse desde que el fin de los regímenes socialistas europeos sumió a Cuba en una crisis económica sin precedentes. Con la década de los noventa sobrevino un «período especial» que significó el aumento de las privaciones y la necesidad de afrontar un futuro cada día menos esperanzador. Mientras el desencanto encontraba justificaciones crecientes, paulatinamente fue perdiendo sentido la oposición entre las ficciones escritas y publicadas dentro de la isla y las que se escribían o al menos se publicaban en el exterior, cada vez más numerosas. Desde entones las estancias de los escritores cubanos en el extranjero no se deben sólo al exilio político o a las misiones diplomáticas, como había ocurrido desde 1959; en los últimos años también se han debido con frecuencia creciente a la búsqueda de posibilidades que no se encuentran en la isla, o a la mera necesidad de sobrevivir. $\mathrm{El}$ interés por Cuba y por la narrativa cubana no ha disminuido en estas circunstancias. A ese interés se debe el éxito cosechado por Marilyn Bobes, Abilio Estévez, Eliseo Alberto, Pedro Juan Gutiérrez y Ronaldo Menéndez, entre otros. Es demasiado pronto para valorar lo que significan en el incesante proceso de la narrativa cubana reciente. 